\title{
Alüminyum Ekstrüzyon Profillerinin Hassas Kesit Ölçümlerinin Görüntü İşleme Teknolojisi İle Gerçekleștirilmesi
}

\author{
Mehmet Yoldaş $^{1 *}$, Cemil Sungur ${ }^{2 *}$ \\ ${ }^{1}$ Konya Teknik Üniversitesi, Mühendislik ve Doğa Bilimleri Fakültesi, Elektrik-Elektronik Mühendisliği Bölümü, Konya, Türkiye (ORCID: 0000-0002-1778-1902) \\ ${ }^{2}$ Konya Teknik Üniversitesi, Mühendislik ve Doğa Bilimleri Fakültesi, Elektrik-Elektronik Mühendisliği Bölümü, Konya, Türkiye (ORCID: 0000-0003-2340-6225)
}

( $1^{\text {st }}$ International Conference on Computer, Electrical and Electronic Sciences ICCEES 2020 - 8-10 Ekim 2020)

(DOI: $10.31590 /$ ejosat.803308)

ATIF/REFERENCE: Yoldaş, M. \& Sungur, C. (2020). Alüminyum Ekstrüzyon Profillerinin Hassas Kesit Ölçümlerinin Görüntü İşleme Teknolojisi İle Gerçekleştirilmesi. Avrupa Bilim ve Teknoloji Dergisi, (Özel Sayı), 190-195.

$\ddot{O} \mathbf{z}$

Bu çalı̧̧mada, alüminyum ekstrüzyon profil üreticilerinin üretim sırasındaki kalite konttoller işlemleri için yapılan temaslı ölçümler yerine temassız ölçüm teknolojisi kullanılarak profil kesit ölçümleri yapılmıştır. köl Temassız ölçüm teknikleri bir çok yönüyle temaslı ölçüm yöntemlerinden daha güvenilirdirler. Temassız ölçüm sonuçları kişiye göre, kullanılan ölçü aletine göre değiş̧iklik göstermeyip stabildir. Yanlış ölçümlerden dolayı üretim verimi düşmekte, gereksiz zaman kaybı yaşanmakta ve işletme maaliyeti artmaktadır. Temassız ölçümlerle bu hataları minimum seviyelere düşürmek hedeflenmiştir. Görüntüleri elde etmek için Canon EOS 400D Cmos kamera ve lens olarak EFS 18-55 mm kullanılmıştır. Aydınlatma kaynağı olarak görüntü işleme ile ölçüm çalışmalarında çok tercih edilen ring aydınlatma tercih edilmiştir. Bu aydınlatma kaynağı seçimi sayesinde görüntülenecek nesne üzerinde homojen aydınlatma sağlanmıştır. Dikkat edilmesi gereken unsurların başında gelen kamera-nesne uzaklığının tüm ölçümlerde aynı olması, kameranın nesneye dik şekilde konumlandırılması, aydınlatma kaynağının cismin üzerine eşit ışık düşürmesi konuları ile ilgili stabil çalışmanın gerçekleştirilmesi için mekanik bir düzenek tasarlanmıştır. Çevresel aydınlatma farklılıklarını ortadan kaldırmak için bu mekanik düzenek kapalı bir kutu içerisini konulmuştur. Görüntüler elde edildikten sonra filtreleme işlemleri gerçekleştirilip görüntüdeki gürültüler giderilmiş̧ir. Ardından bir takım işlemlerle kenar belirleme işlemleri gerçekleştirilmiştir. Kontor özelliği kullanılarak kenar çizgileri çizdirilmiştir. Bazı matematiksel işlemler yapılarak istenilen kesitlerin ölçümleri gerçekleştirilmiştir. Piksel-mm dönüşümlerini gerçekleştirmek için ölçüleri kesin bilinen referans nesneler kullanmıştır. Çalışmalar OpenCv kütüphanesi kullanılarak PyCharm uygulmasında çalışlarak gerçekleştirilmiş̧ir. Profil kesit ölçümleri temassız ölçüm yöntemleri ike gerçekleştirildikten sonra literatür çalışmlarındaki temaslı kesit ölçüm hata payları ile temassız kesit ölçüm hata payları karşılaştırılmışır. Yapılan çalışmadaki hata payları mekanik ölçüm cihazları ile gerçekleştirilen temaslı ölçüm tekniklerindeki hata paylarından daha düşüktür.

\section{Performing Precision Section Measurements of Aluminum Extrusion Profiles with Image Processing Technology}

\begin{abstract}
In this study, profile cross-section measurements were made using non-contact measurement technology instead of contact measurements for quality control processes during production of aluminum extrusion profile manufacturers. Non-contact measurement techniques are in many ways more reliable than contact measurement methods. Non-contact measurement results are
\end{abstract}

\footnotetext{
* Sorumlu Yazar: Konya Teknik Üniversitesi, Mühendislik ve Doğa Bilimleri Fakültesi, Elektrik-Elektronik Mühendisliği Bölümü, Konya, Türkiye, ORCID: 0000-0002-1778-1902, mehmetyoldass@gmail.com
} 
stable and do not vary depending on the person and the measuring device used. Due to incorrect measurements, production efficiency decreases, unnecessary time loss is experienced and operating cost increases. It is aimed to reduce these errors to minimum levels with non-contact measurements. A Canon EOS 400D Cmos camera was used to acquire the images and EFS 18-55mm as lens was used. Ring lighting, which is mostly preferred in image processing and measurement studies, was preferred as the lighting source. Thanks to this lighting source selection, homogeneous lighting is provided on the object to be imaged. A mechanical mechanism has been designed in order to perform a stable study regarding the subjects of camera-object distance being the same in all measurements, the positioning of the camera perpendicular to the object, and the equal light of the illumination source on the object. This mechanical mechanism is placed in a closed box to eliminate environmental lighting differences. After the images were acquired, filtering processes were performed and the noise in the image was removed. Then, edge determination processes were carried out with some operations. Edge lines are drawn using the contor feature. The desired cross sections were measured by doing some mathematical operations. It used reference objects whose dimensions are precisely known to perform pixel-mm conversions. The studies were carried out by working in the PyCharm application using the OpenCv library. After conducting the profile section measurements with non-contact measurement methods, the contact section measurement error margins and non-contact cross section measurement errors in literature studies were compared. The margin of error in the study is lower than the margin of error in contact measurement techniques performed with mechanical measuring devices.

Keywords: Non-contact measurement, Cross-section control, Cross-section measurement, Two-dimensional measurement, Noncontact quality control

\section{Giriş}

Alüminyum profil üretiminde kalite kontrol işlemleri, bilim ve teknolojinin gelişmesiyle büyük boyutlu ve karmaşık yapıll, bükümlü profillerin ölçümlerinin gerçekleştirilmesi manuel test teknolojisi ile endüstrinin ihtiyaçlarını karşılayamamaktadır [1]. Bu manuel ölçüm yöntemleri insan hatalarına açık, stabil olmayan sonuçlar vermektedir. Boyut parametresi ölçümü, mekanik parçaların üretim sürecindeki kilit noktadır, ancak çeşitli geleneksel ölçüm yöntemleri vardır. Örneğin: kaliperler, göstergeler, mikrometre, vb. [2]. Bu yöntem yerine görüntü işleme kullanıldığında yüksek doğruluk, büyük zaman tasarrufu, düşük maliyet gibi avantajlar sağlayacaktır [3]. Ayrıca modern üretim teknolojileri gün geçtikçe daha minyatür, karmaşık ve kırılgan hale gelen yüzeylerin temaslı ölçümleri için her zaman uygun değildir [4]. Görüntü işleme teknolojisi ile ölçüm metodundaki hata payları ve hassasiyetler istenen aralıklarda olması durumunda birçok avantajından dolayı temaslı ölçümden daha iyi bir ölçüm yöntemi olacaktır.

Alüminyum ekstrüzyon kalite kontrol süreçleri de oldukça hassas çalışmalar gerektirmektedir. Günümüzde temaslı ölçü aletleriyle kalite kontrol işlemlerini gerçekleştiren birçok üretici problemler yaşamaktadırlar. Bu ölçüm yöntemiyle detay kesit sayısı fazla olan profillerin ölçümleri uzun süre çalışma gerektirmektedir. Ölçü aletlerinin sürekli kalibrasyonlarının takibi yapılmalı ve kalibrasyon süresi geçen ölçü aletlerinin kullanımı sonucu hatalar meydana gelebilmektedir. İnsanların temaslı ölçü aletlerin kullanımı esnasında cihazı sert ya da yumuşak temasla kullanmaları arasında büyük hata payları ortaya çıkmaktadır. Uzunluk, çap, iç açıklık, genişlik gibi farklı ölçümler farklı ölçü cihazları gerektirmektedir. Bu anlamda hem personelin bütün ölçü aletlerini kusursuz kullanma yeteneği hem de bütün cihazların kusursuz ve kaliteli cihazlar olması gerekmektedir. Bunların hepsi işletme maliyetini artıran sebeplerdendir. Bazı karmaşı şekilli profillerin birçok ölçümünü de mekanik ölçü aletleri ile yapmak mümkün değildir ya da çok zaman almaktadır. Bu sebeplerden dolayı eğer görüntü işleme teknolojisi ile yapılan ölçüm çalışmaları, üretim toleranslarını sağlayacak şekilde gerçekleştirebilirse, sağladığı diğer faydalardan dolayı temaslı ölçü aletlerinden daha makul bir yöntem olacaktır.

Alüminyum profillerde yapılan görüntü işleme çalışmaları literatür araştırması yapıldığında bir çoğunun yüzey sorunları tespit etme üzerine olduğu görülmektedir. Alüminyum profillerde görüntü işleme ile kesit ölçümü yapılan bir çalışmaya rastlamamıştır. Bu bakımdan özgün bir çalışma olmuştur. Benzer çalışmalara bakıldığında temel geometrik şekil tespiti çokça görülmektedir. Sebze meyve sınıflandırma işlemlerinde kenarlar tespit edildikten sonra en çok çap belirleme işlemleri yapılmaktadır [1], [5], [6]. Tıp alanında yapılan çalışmalara bakıldığında belirlenen iki nokta arası ölçümler yapılmıştır [7]. Metal birçok ürünün çap ölçümleri [8], [9] ,dış kenar uzunlukları ölçülmüştür. Konfeksiyon alanında kıyafetlerin belirli iki noktaları arası ölçümleri gerçekleştirilmiştir[10], [11]. Yapılan çalışmalar gözden geçirildiğinde çok fazla hassas olmayan ve genellikle nesnelerin dış hatlarında ölçümler gerçekleştirilmiştir. Bu çalışmada karmaşık şekle sahip ve yüksek yansıtma özelliği olan alüminyum profillerin iç kesit ölçüleri kontur bulma ve çizdirme yöntemiyle ölçülmüştür. Hata payları hesaplanmıştır. Bu çalışmada 2. Bölüm kullanılan mekanik düzenek, kamera, lens, aydınlatma unsurları, zemin özellikleri, referans nesne, kamera kalibrasyonu ve yazılım sistemi hakkında detayları içermektedir. 3. Bölümde ölçüm sonuçları ve hata payı hesaplaması bulunmaktadır. 4. Bölümde ise elde edilen çıkarımlar ve tavsiyeler bulunmaktadır.

\section{Materyal ve Metot}

Yapılan çalışmalar temelde iki kısımdan oluşmaktadır: donanın sistemi, yazılım sistemi. Donanım sistemi, yapılan çalışmada elde edilecek görüntülerin sağlıklı bir şekilde elde edebilmesi için çevre koşullarının sabitliğini sağlayan kısımdır. Donanım kısmındaki uyumsuzluklar ya da yetersizlikler yazılım sisteminde yapılacak çalışmaları zorlaştırabilir ya da imkânsız kılabilir. Yazılım sistemi, elde edilen görüntünün bir takım filtrelerle, algoritmalarla işlemlere tabi tutulup, kullanıcıya anlamlı bir çıktı veren kısımdır. 


\subsection{Deney Düzeneği}

Deney düzeneği Şekil 1 de görüldüğü gibi aydınlatma kaynağı, kamera, kablolu deklanşör ve mekanik düzenekten oluşmaktadır. Çalışmalarda Canon EOS 400D Cmos kamera kullanılmıştır. Kullanılan lens EFS 18-55 mm şeklindedir. Farklı literatür çalışmalarında kullanılan yada tavsiye edilen teknikleri, yöntemleri, malzemeleri donanımları aynı anda kullanarak çalışmanın verimliliğini artırmak için bu tasarım gerçekleştirilmiştir. Tasarım çalışmaları Solidworks programında çizilip mekanik parçalar belirlenmiştir. Ardından montaj işlemleri gerçekleştirilmiştir.

\section{Şekil 1. Ölçü Kontrol İstasyonu}

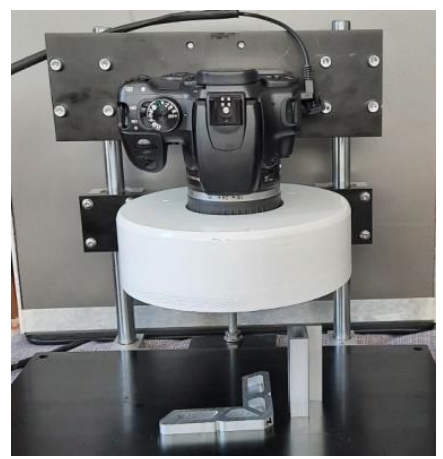

Görüntü işleme teknolojisi ile ölçüm çalışmalarında bir takım problemler vardır. Bu problemlerin başında aydınlatma sorunları vardır. İyi bir görüntü ancak doğru seçilmiş aydınlatma kaynağı ve ortamı ile elde edilebilir [12]. Uygun aydınlatma, sistemin genel etkisini artırarak bilgilerin daha sonra analiz edilmesini kolaylaştırabilir [3]. Aydınlatma ile ilgili buna benzer birçok uyarı ya da bilgilendirme birçok kaynakta mevcuttur. AC beslemeli aydınlatma kaynakları frekanstan etkilenerek stabilliğini koruyamazlar. Bu durum da görüntüler üzerinde farklı sonuçlar alınmasına neden olmaktadır [4]. Bu bilgiler kullanılarak DC beslemeli aydınlatma kaynağı kullanmaya karar verilmiştir. Kameradan elde edilen görüntü, kamera açısı, ortam aydınlatması, toz ve benzeri diğer faktörlerden kolayca etkilenebilecek durumdadır [12]. Bu bilgiler doğrultusunda kamera-nesne mesafesi, aydınlatma kaynağı nesne mesafesi ve kameranın nesneye göre açısı için mekanik düzen tasarlanmıştır. Bu mekanik düzenek sayesinde kamera-nesne uzaklığı sabit tutularak bu mesafedeki farklılıklardan dolayı ölçü farklılıklarının önlenmesi amaç edinilmiştir. Kamera nesne mesafesi değiştikçe nesnedeki büyüme ya da küçülme teorik hesaplardaki gibi liner değişim göstermez [13]. Bu bakımdan dikkat edilmelidir. Aydınlatma kaynağı- nesne uzaklığı ayarlanabilir olması için mekanik ayarlanabilir ve sabit tutulabilir şekilde mekanik düzenek kurulmuştur. Kameranın nesneye göre dönüklüğü ayarlamaları için dijital su terazisi kullanılmıştır. Mekanik düzenek dengesi ve ardından kamera dengesi ayarlanmıştır. Literatürde kamera nesne dönüklüğü çalışmaları yazılımsal olarak da yapılmıştır [14].

Aydınlatma unsurunun sabit olması için sistemin kapalı bir ortam içerisinde tutulması ve ışık şiddetinin kontrol altına alınması da sistemin verimliliğini artıracaktır [12]. Çevresel şartlardan etkilenmeyi sıfira indirmek için numunelerin görüntüsünün alındığı mekanik düzenek Şekil 2'de olduğu gibi kapalı bir kompozit kutu içerisine alındı. Fotoğrafların çekimi için soket bağlantıları yapılıp kablolu bir deklanşör kumandası dışarıya çıkarıldı. Aydınlatma kaynağının görüntülenecek nesneye olan yönü ile ilgili literatür çalışmalarında kullanılmıştır. Arka aydınlatma ile elde edilen görüntü mükemmel bir kontrasta sahip olacaktır. Kontrast derecesi, kenar taramasının doğru olup olmadığını hemen etkileyebilir [3]. Arka plan aydınlatma şeması benimsendiğinde, görüntüleme en nettir ve kenarın konturu da çok nettir [3]. Yüksek kontrastlı görüntüler elde etmek ve sonraki görüntü işlemeyi kolaylaştırmak için arka aydınlatma modu benimsenmiştir [15]. Bu sistemde arka ışı, mekanik parçalar için ideal aydınlatma türüdür [16]. Bu ifadeler gibi birçok ölçü çalışmasında geri aydınlatma seçilmiştir.

\section{Şekil 2. Ölçü Kontrol Istasyonu Kutusu}

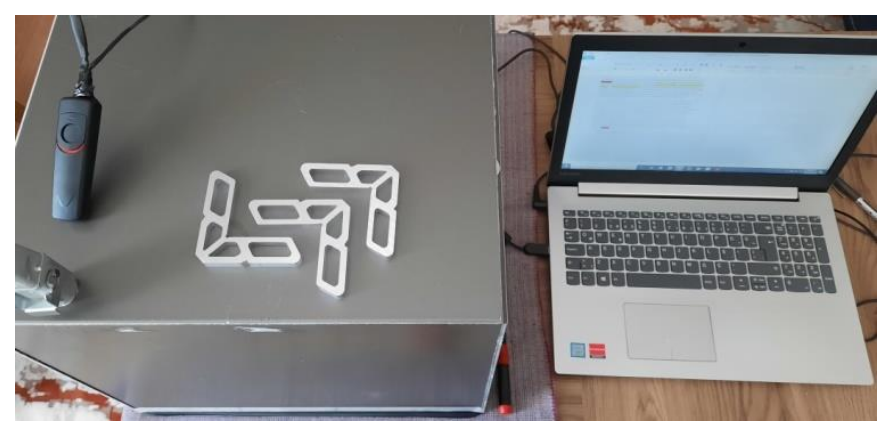

Kesit ölçüm çalışmalarında bir diğer sorun kameranın kalibrasyonu olmuştur. Bununla yapılan çalışmalarda genellikle referans nesneler kullanılmıştır. Yapılan çalışmalardan birinde elma kesitleri ölçümünde referans nesne olarak cetvel konulmuş ve mm- piksel dönüşüm oranı bulunmuştur [4]. da yapılan diğer bir çalışmada görüntüsü alınacak nesnenin altına sabit ölçülü ölçüm nesnesi konup dönüşüm oranı bulunmuş̧ur [16]. Başka bir çalışmada özellikleri bilinen iki adet referans nesne ile birlikte işlem yapılacak nesne aynı karede görüntülenmiş, bilinen nesnenin tekabül ettiği piksel değerinden dönüşüm oranı belirlenmiştir [14]. Benzer şekilde bir çalışmada referans oluşturması için numunenin hemen yanına siyah renkte, alanını daha önceden bilinen bir dairesel kesit eklenmiştir. Bilinen nesnenin çapına tekabül eden piksel değeri ile ölçülmek istenen kesiti arasında dönüşüm gerçekleştirilip ölçüm 
gerçekleştirilmiştir [17]. Bu çalışmada kalibrasyon kontrol metali referans olarak alınmıştır. Ayrıca algılanacak nesneyi arka plandan kolay ayırmak için Şekil 1 deki gibi zemin siyah olarak seçilmiştir [6]. Benzer şekilde diğer bir çalışmada düzeneğin iç yüzeyi denemeler sırasında en iyi görüntünün elde edilebilmesi için siyah renge boyanmıştır [4]. Bu çalışmada da zemin siyah renklidir. Bunlara ilave olarak aydınlatma kaynağı armatürü beyaz renkli statik boya ile boyanmıştır. Bu sayede diğer renklere göre daha fazla yansıtma özelliği kullanılmaktadır.

\subsection{Yazılım Çalıșması}

Literatür çalışmalarında görüntü işleme teknolojisi ile nesne kesiti ölçüm çalışmalarına bakıldığında bu işlemler genel olarak yazılımsal açıdan Şekil 3'deki gibidir. Alüminyum ekstrüzyon sektöründe üretilen Şekil 4'deki orijinal profilin kesit ölçümleri yapılmıştır.

\section{Şekil 3. Literatür Çalışmalarındaki Genel Akış Diyagramı}

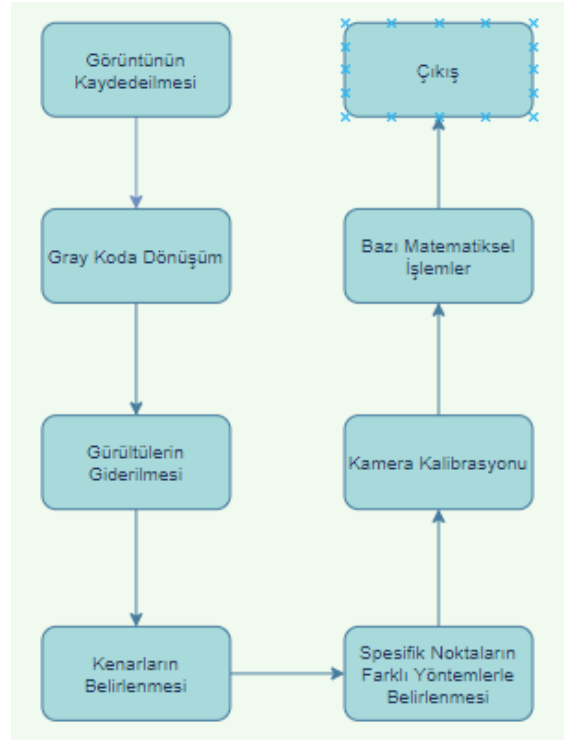

Görüntünün kaydedilmesi aşamasından sonra ilk iş gürültülerin giderilmesidir. Elde edilen renkli görüntü muhtemelen çok fazla gürültüye sahip olacaktır. Geri kalan adımlara geçmeden önce, görüntüye bir Gauss bulanıklığı uygulanır, o yumuşatılır ve böylece gürültü azaltılır [18]. . Çalışmada öncelikle kameradan görüntü elde edilmiş ve akabinde lüzumsuz addedilen gürültü kaldırma işlemleri gerçekleştirilmiştir [7]. Profilden elde edilen görüntülerin gürülttülerinin giderilmeden işlem yapılması durumunda profili oluşturan kontur sayısı yanlış hesaplanmakta ve bu durum algoritmanın başarısını olumsuz yönde etkilemektedir [12]. Bu çalışmada da tuz biber filtresi olarak meşhur olan Gaussian filtresi kullanılmıştır. Bazı literatür çalışmalarında ise Medyan filtre kullanılmıştır[2], [16]. Görüntü işlemede çok yaygın olarak kullanılan medyan filtre doğrusal olmayan bir filtrelemedir ve görüntüde bir tür gürültü azaltma amaciyla kullanılır.

İkinci işlem gri tonlamaya dönüşüm işleme yapmaktır. Bir korelasyon algoritması kullanarak, toplanan renkli bir görüntünün gri tonlamalı bir görüntüye dönüştürülmesi işlemidir. Gri tonlama işleme, görüntünün gri değerini 0-256 aralığına sahip yeni gri bir aralığa eşler. Bu değer bir pikselin R,G,B piksel yoğunluk değerlerinin ortalama değeri olarak belirlenen sayıya göre 0-256 aralığına sahip gri tonlama ile yeniden ifade edilme şeklidir. Bu da görüntünün belirli özelliklerini tanımlamayı ve sonraki görüntü işlemeyi kolaylaştırır.

Üçüncü aşama olarak görüntüye segmentasyon yaparak çalışmak istediğimiz görüntünün arka plandan ayrılması sağlanır. Bu çalışma ayrıca resim boyutunu küçülterek hız artışı da sağlar. Segmentasyon işlemi ile alt ve üst sınırlarlar belirlenip binary dönüşüm elde edilmiş olur. Bu sayede istenilen bölgelerin beyaz, arka planın siyah olması beklenir. Bu özellik kullanılarak kenar belirleme işlemi gerçekleştirilecektir.

Dördüncü aşama olarak kenarların belirlenmesinde farklı kenar belirleme algoritmaları mevcuttur. Yapılan literatür çalışmasında görüntü işleme teknolojisi ile kesit belirleme işlemlerinde Canny kenar algılama yoğun olarak tercih edilmiştir [14], [7], [3], [18], [12], [15]. Bunun haricinde kenar belirlemek için Hough transform yönteminden faydalanılan çalışmalar da olmuştur[16], [2], [19], [8]. Bu çalışmada kenar belirleme de Canny algoritması kullanılmıştır.

Canny kenar belirleme algoritması uyguladıktan sonra kenarlar belirlenmiş gibi bazen görünebiliyor fakat daha dikkatli bakılması durumunda kesintiler olabiliyor. Kontor uygulaması yaptığınızda kenarların kesikli olduğunu tespit edebilirsiniz. Problem oluşmaması adına ilk deneme Canny kenar algılama yapıldıktan sonra morfolojik işlemlerden dilate işlemini de dahil ederek gerçekleştirildi. Şekil 4'de görüldüğü gibi bu işlem sonrasında gereksiz birçok kontor noktası meydana gelmiştir. Dilate işlemi yapılmadan kontor işlemi uygulandıktan sonra sağıklı sonuçlar elde edilmiştir. Dilate işlemi uygulamadan yapılan çalışmada daha önceden belirtilen bir kesitin uzunluğu piksel cinsinden bulunmuştur. 
Beşinci aşama spesifik noktaların belirlenme aşamasıdır. Bu aşamada literatürde farklı uygulamalar görülmektedir. Tıp alanında yapılan bir çalışmada da görüntü üzerindeki iki noktaya mouse ile manuel olarak işaret konulmuş ve bu iki nokta arasındaki pikseller bulunmuştur [7]. Bu uygulamadan farklı olarak referans görüntünün piksel yoğunluk değerleri binary forma dönüştürüldükten sonra sisteme kaydedilmiş ve ölçülmek istenen objenin piksel yoğunluk değerleri binary forma dönüştürülüp iki görüntünün aynı satır ve sütundaki piksel yoğunluk değerlerine XOR işlemi yapılmıştır [4]. Diğer bir yöntemse kenarları belirlenen görüntülerin sınır hatları boyunca kesintisiz hatları belirleyen ve istenirse çizen yöntem olan kontor yöntemidir. Konuyla ilgili çalışmaya literatür çalışmalarında sıkça rastlanmaktadır[16], [10], [12], [20], [15]. Bu çalışmada da kontor yöntemi kullanılmıştır. Bu yöntemle birlikte profilin kenarları ve köşe noktaları belirlenmiştir. Kontorler çizdirildikten sonra matematiksel işlemlerle istenilen pozisyonların x ve y pozisyonları piksel cinsinden elde edildi. İki nokta arası mesafe $|A B|=\sqrt{\left(x_{1}-x_{2}\right)^{2}+\left(y_{1}-y_{2}\right)^{2}}$ formülü kullanılarak elde edilmiştir. Elde edilen uzaklık piksel cinsinden uzaklığın ifade edilişşseklidir. Referans nesne kullanılarak, referans nesnenin görüntüde tekabül ettiği piksel değerleri bulunmuştur. Gerçek değeri ile oranlayarak mm- piksel dönüşümü formülize edilmiştir. Referans nesne ilk denemelerde aynı karede alınmıştır. Fakat aynı karede görüntüsü alınan cisimler aydınlatma kaynağından gelen ışınları yansıttığı için kamera-nesne uzaklığı değişmeden ayrı görüntülerde piksel değerleri ölçülmüştür.

Şekil 4. Orijinal Görüntüden Piksel Ölçümüne Kadar Görüntü Iş̧leme Aşamaları

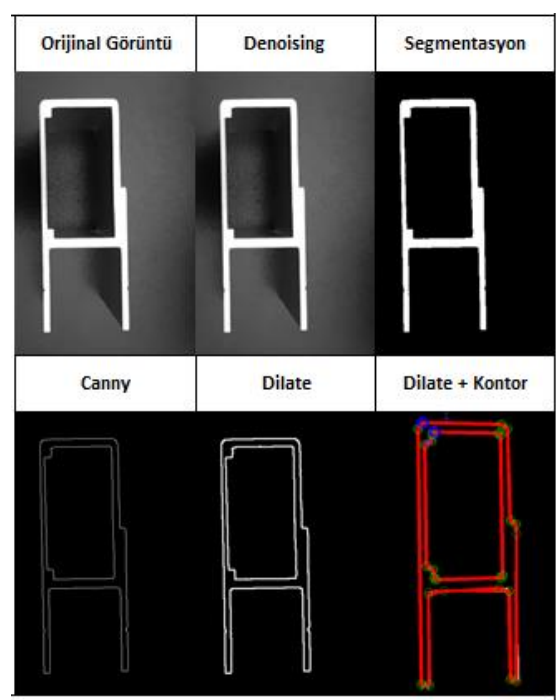

Şekil 5. Orijinal Profil Görüntüsü ve Bir Kesitin Ölçüsü Bulunmuş Profil Görüntüsü

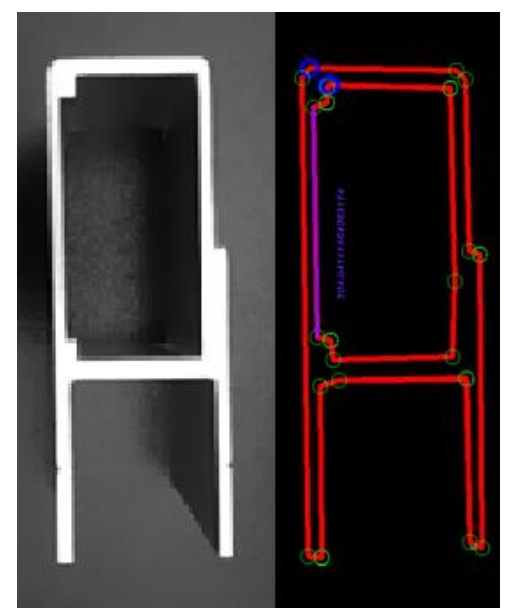

\section{Araştırma Sonuçları ve Tartışma}

$\mathrm{Bu}$ çalışmada alüminyum ekstrüzyon sektöründe üretilen profillerden üretim esnasında küçük numuneler alarak toleranslara uygun olup olmadığı ile ilgili görüntü işleme teknolojisi ile belirlenen kesit ölçümü işlemleri gerçekleştirilmiştir. Mekanik sistem ve yazılım sisteminden oluşan ölçü kontrol sisteminde referans küpü ile denemeler yapılmıştır. Yapılan çalışmada referans nesnenin kesitine (50 mm kesitli alüminyum küp) tekabül eden piksel sayısı 390,38'dir. 1 piksel 0,1273 mm ye tekabül etmektedir. Ölçülmek istenen nesne aynı kamera-nesne uzaklığında 304,04 piksel gelmektedir. Gerçekte olması gereken 38.70 mm olan kesit 38,94 olarak ölçülmüştür. Hata payı \%0,6 olarak belirlenmiştir. Bu hata payları ile [12] numaralı literatür çalışmasında temaslı ölçüm cihazları ile yapılan ölçüm hatalarının minimumum değerine yaklaşılmıştır. Bunun yanı sıra zaman anlamında temaslı ölçüm cihazlarından daha hızlı ölçüm gerçekleştirilecektir. Hata payının en büyük nedenleri arasında ölçülmek istenen profil görüntüsünün gürültü giderme 
işlemleri olun Gaussian filtre işlemleri olmuştur. Ne kadar fazla Gaussian sabitini artırsanız keskin çizgiler yuvarlanmaya ve kendi özünü kaybetmeye başlayacaktır.

\section{Sonuç}

Literatür çalışmaları incelendiğinde görüntü işleme teknikleri ile alüminyum ekstrüzyon profilleri kesit ölçüm üzerine çalışmaya rastlanmamıştır. Genellikle alüminyum profillerle yapılan çalışmalar yüzey sorunları üzerine olmuştur. Bu anlamda özgün bir çalışma gerçekleştirilmiştir. Daha sonraki çalışmalarda ilave çalş̧̧alarda eklenebilir. Şu anki haliyle sadece iç yükseklik ölçümü değerlendirildiğinde temaslı ölçüm ortalama temaslı cihazların minimum hatalı şekliyle kullanılabilir şekildedir.

Alüminyum profil ölçüm sistmei hatası \%0.6 olarak hesaplanmıştır. Hata payının azaltılması için yapılacak bazı çalışmalar şunlardır: Profilin yüzeyindeki aydınlatmanın homojenliğini bozan testere izleri farklı bir yöntemle kesilmeli ya da kesimden sonra boyama yoluyla bu çizgiler kaybedilebilirse hata payları düşürülebilir. Literatür çalışmalarından faydalanılarak gürültü yok etme metotlarından ölçü bozukluğu yapmayan filtre araştırması yapılabilir. Ayrıca zemin mekaniği bu projede alüminyumdan yapılmıştır. $\mathrm{Bu}$ mekanik parçada aynı şekilde yüksek yansıma özelliklerine sahip olduğundan dolayı profilin yan yüzeylerinde parlaklıklar oluşturup görüntüde bozulmalar meydana getirmiştir. Yansıtıcı özelliği düşük olan malzemelerle zemin oluşturulmasına dikkat edilmelidir. Çözünürlük ve yüksek odaklanma özelliği olan kameralarla çalışılması da hata payının düşmesine olumlu yönde etki edecektir.

\section{Kaynakça}

[1] Ilunga, J. C. M., \& Mpoyi, D. K. (2019). Contrôle dimensionnel des pièces mécaniques sans contact basé sur la transformation Hough dans le traitement d'image. International Journal of Innovation and Applied Studies, 26(2), 426-432.

[2] Li, Y. F., Han, X. X., \& Li, S. Y. (2015, October). Non-contact dimension measurement of mechanical parts based on image processing. In 2015 8th International Congress on Image and Signal Processing (CISP) (pp. 974-978). IEEE.

[3] Zhao, Z., Wu, D., \& Zhang, L. (2018). Research on Measurement of Mechanical Parts Based on Vision. MS\&E, 394(3), 032083.

[4] Sofu, M. M., Er, O., Kayacan, M. C., \& Cetişli, B. (2013). Elmaların görüntü işleme yöntemi ile sınıflandırılması ve leke tespiti. Glda Teknolojileri Elektronik Dergisi, 8(1), 12-25.

[5] Sabliov, C. M., Boldor, D., Keener, K. M., \& Farkas, B. E. (2002). Image processing method to determine surface area and volume of axi-symmetric agricultural products. International Journal of Food Properties, 5(3), 641-653.

[6] CÖMERT, O., HEKIM, M., \& Kemal, A. D. E. M. (2017). Weight and Diameter Estimation Using Image Processing and Machine Learning Techniques on Apple Images. Uluslararası Mühendislik Araşttrma ve Geliştirme Dergisi, 9(3), 147-154.

[7] Osmanoğlu, U. Ö., Mutlu, F., Gürsoy, H., \& ŞANLISOY, S. (2016). Görüntü işleme ve analizinin tıpta kullanımı ve bir uygulama. Osmangazi Tip Dergisi, 41(1), 6-16.

[8] Derganc, J., Likar, B., \& Pernuš, F. (2003). A machine vision system for measuring the eccentricity of bearings. Computers in industry, 50(1), 103-111.

[9] Salloom, M. Y. (2016). MACHINE VISION APPLICATION IN MANUFACTURING: INSPECTION OF DIMENSIONS. Iraqi journal of mechanical and material engineering, 16(3), 268-284.

[10] Karunamoorthy, B., \& Ramprabu, J. A Novel Method Of real Time Cloth Size Measurement Algorithm Based On Fpga Platform.

[11] Ural, Ö., \& Vural, T. (2020). Measurement Control of Ready-Made Garments with Image Analysis Methods. Journal of Textile \& Apparel/Tekstil ve Konfeksiyon, 30(1).

[12] Akdoğan, M. (2018). Karmaşık şekilli mamullerin görüntü işleme teknikleri kullanılarak gerçek zamanlı boyut kontrolü (Doctoral dissertation, Selçuk Üniversitesi Fen Bilimleri Enstitüsü).

[13] Jawad, Huda M.\& Husain, Tahseen. (2017). Measuring Object Dimensions and its Distances Based on Image Processing Technique by Analysis the Image Using Sony Camera.

[14] GÜNEŞ, H., BURMABIYIK, A., KELEŞ, S., \& AKDAŞ, D. GÖRÜNTÜSÜ ALINAN BİR NESNENIN REFERANS BİR NESNE YARDIMIYLA BOYUTLARININ, ALANININ VE AÇISININ HESAPLANMASI.

[15] Li, B. (2018). Research on geometric dimension measurement system of shaft parts based on machine vision. EURASIP Journal on Image and Video Processing, 2018(1), 101.

[16] Zhang, T., Luo, Y., Wang, X., \& Wang, M. (2010, December). Machine vision technology for measurement of miniature parts in narrow space using borescope. In 2010 International Conference on Digital Manufacturing \& Automation (Vol. 1, pp. 904-907). IEEE.

[17] ÖZTÜRK, F., BAŞ, M. H., \& KILIÇ, S. (2013). Malzemelerde Sünekliğin Görüntü İşleme Yöntemiyle Ölçülmesi. Niğde Ömer Halisdemir Üniversitesi Mühendislik Bilimleri Dergisi, 2(2), 34-42.

[18] Shetty, S. J. (2019). Vision-based inspection system employing computer vision \& neural networks for detection of fractures in manufactured components. arXiv preprint arXiv:1901.08864.

[19] Baygin, M., Karakose, M., Sarimaden, A., \& Erhan, A. K. I. N. (2017, September). Machine vision based defect detection approach using image processing. In 2017 international artificial intelligence and data processing symposium (IDAP) (pp. 1-5). Ieee.

[20] Baharatti Priya, Sudha. Image Processing Based Fault Detection and Isolation for Mechanical Components. International Journal of Engineering and Advanced Technology (IJEAT), 2019, 8.6S. 